Repository of the Max Delbrück Center for Molecular Medicine (MDC) in the Helmholtz Association

http://edoc.mdc-berlin.de/14434

CYP-13A12 of the nematode Caenorhabditis elegans is a PUFAepoxygenase involved in behavioural response to reoxygenation

Keller, J., Ellieva, A., Ma, D.K., Ju, J., Nehk, E., Konkel, A., Falck, J.R., Schunck, W.H., Menzel, R.

This is the final version of the manuscript. The original article has been published in final edited form in:

Biochemical Journal

2014 Nov 15 ; 464(1): 61-71

doi: $10.1042 / B J 20140848$

Publisher: Portland Press 


\section{CYP-13A12 OF THE NEMATODE C. ELEGANS IS A PUFA-EPOXYGENASE INVOLVED IN BEHAVIOURAL RESPONSE TO REOXYGENATION}

Julia Keller ${ }^{* 1}$, Alexandra Ellieva ${ }^{* 1}$, Dengke K. $\mathrm{Ma}^{\dagger}$, Jingjuan $\mathrm{Ju}^{\ddagger}$, Erik Nehk ${ }^{*}$, Anne Konkel ${ }^{\S}$, John R. Falck ${ }^{\#}$, Wolf-Hagen Schunck ${ }^{\S}$ and Ralph Menzel $^{* 2}$

* Humboldt-Universität zu Berlin, Department of Biology, Freshwater and Stress Ecology, Späthstr. 80/81, 12437 Berlin, Germany

${ }^{\dagger}$ Department of Biology, MIT, Cambridge, MA 02139, USA

${ }^{\ddagger}$ Department of Occupational and Environmental Health, School of Public Health, Southeast University Nanjing, China

${ }^{\S}$ Max Delbrück Center for Molecular Medicine, Robert-Rössle-Str. 10, 13125 Berlin, Germany

\# Department of Biochemistry, University of Texas Southwestern, Dallas, Texas 75390, USA

${ }^{1} \mathrm{JK}$ and AE contributed equally

${ }^{2}$ To whom correspondence should be addressed (email ralph.menzel@biologie.hu-berlin.de)

SHORT TITLE: CYP-13A12 of C. elegans is a PUFA-epoxygenase 


\section{SYNOPSIS}

A specific behavioural response of Caenorhabditis elegans, the rapid increase of locomotion in response to anoxia/reoxygenation called the O2-ON response, has been used to model key aspects of ischemia/reperfusion injury. A genetic suppressor screen demonstrated a direct causal role of CYP-13A12 in this response and suggested that CYP-eicosanoids, which in mammals influence the contractility of cardiomyocytes and vascular smooth muscle cells, might function in C. elegans as specific regulators of the body muscle cell activity. Here we show that co-expression of CYP-13A12 with the NADPH-CYP-reductase EMB-8 in insect cells resulted in the reconstitution of an active microsomal monooxygenase system that metabolised EPA (eicosapentaenoic acid) and also AA (arachidonic acid) to specific sets of regioisomeric epoxy and hydroxy derivatives. Main products included 17,18-EEQ (epoxyeicosatetraenoic acid) from EPA and 14,15-EET (epoxyeicosatrienoic acid) from AA. Locomotion assays showed that the defective O2-ON response of C20-PUFA-deficient, $\Delta^{-12}$ and $\Delta^{-6}$ fatty acid desaturase mutants (fat-2 and fat-3, respectively) can be restored by feeding the nematodes AA or EPA, but not ETYA (eicosatetraynoic acid), a non-metabolisable AAanalogue. Already short-term incubation with 17,18-EEQ was sufficient to rescue the impaired locomotion of the fat-3 strain. The endogenous level of free 17,18-EEQ declined during anoxia and was rapidly restored in response to reoxygenation. Based on these results, we suggest that CYP-dependent eicosanoids such as 17,18-EEQ function as signalling molecules in the regulation of the O2-ON response in C. elegans. Remarkably, the exogenously administered 17,18-EEQ increased the locomotion activity already under normoxic conditions and was effective not only with C20-PUFA mutants but to a lesser extent also with wild-type worms.

KEYWORDS: $\quad$ Eicosanoids; Polyunsaturated fatty acids; Caenorhabditis elegans; Cytochrome P450; Reoxygenation; 17,18-EEQ

ABBREVIATIONS USED: AA, arachidonic acid; CID, collision-induced dissociation; COD, carbon monoxide difference; CPR, NADPH-CYP reductase; CYP, cytochrome P450; DiHETE, dihydroxyeicosatetraenoic acid; DTT, dithiothreitol; EGL, egg laying defect; EGLN, EGL nine; EEQ, epoxyeicosatetraenoic acid; EET, epoxyeicosatrienoic acid; EPA, eicosapentaenoic acid; ETYA, eicosatetraynoic acid; GFP, green fluorescent protein; GPCR, $G$ protein-coupled receptor; HEET, hydroxyepoxyeicosatrienoic acid; HEPE, hydroxyeicosapentaenoic acid; HETE, hydroxyeicosatetraenoic acid; HIF, hypoxia inducible factor; LC, liquid chromatography; MC, pharyngeal marginal cell; MS, mass spectrometry; NGM, nematode growth medium; PUFA, polyunsaturated fatty acid; RP, reversed-phase 


\section{INTRODUCTION}

Oxygen deprivation upon restriction of blood supply followed by reperfusion and concomitant reoxygenation causes tissue injury and is involved in the initiation of various human pathologies including ischemic stroke, myocardial infarction, and acute kidney injury [1]. The nematode $C$. elegans can survive at a wide range of oxygen concentrations, but exhibits an aerotaxis behaviour prompting the worms to migrate to their preferred oxygen concentration of about $10 \%$ [2]. Upon anoxia/reoxygenation, C. elegans shows the so-called "O2-ON" behavioural response that is characterised by a rapidly increased locomotion speed [3, 4]. Recent studies suggest that evolutionarily conserved pathways contribute to ischemiareperfusion injury in mammalian cells and to the O2-ON response in C. elegans [5].

Mammals and C. elegans share the expression of an evolutionarily conserved family of $\mathrm{O}_{2}$ dependent prolyl hydroxylases, EGLN2 and EGL-9, respectively. Prolyl hydroxylation regulates HIF (hypoxia-inducible transcription factor) levels in C. elegans as well as in mammals and, thus, links hypoxia to HIF-mediated physiological responses [6-10]. EGL-9 inactivation blocks the O2-ON response of $C$. elegans [3, 4]. A screen for mutations restoring the defective O2-ON response in an EGL-9 deficient strain, egl-9(n586), identified a gain-offunction allele of the cyp-13A12 gene that encodes a CYP (cytochrome P450) enzyme [5]. C. elegans harbours several CYP genes that are homologous to mammalian CYP isoforms [11]. CYP3A4, a CYP enzyme predominantly expressed in the liver, but also in the brain and other extrahepatic tissues [12, 13], is the most closely related human homolog of CYP-13A12 (32 $\%$ amino acid identity). Human CYP3A4 has been primarily known for its important role in liver microsomal drug metabolism but also contributes to the metabolism of a wide variety of endogenous substrates including the epoxidation of AA (arachidonic acid; $\mathrm{C}_{20: 4, n-6}$ ) and anandamide [14, 15]. Further work revealed also the emb-8 gene, encoding the worm's homolog of mammalian CPRs (NADPH-CYP reductase) [16], as essential for the O2-ON response [5]. Taken together, these results of genetic analysis indicated that a microsomal monooxygenase system composed of a CYP and CPR component is involved in mediating the locomotion behaviour of $C$. elegans; however, the substrate specificity of this enzyme as well as the potential role of its metabolites in eliciting the O2-ON response remained unclear.

Suggesting an important role for C20-PUFAs (polyunsaturated fatty acids) and/or their metabolites in the O2-ON response, $\Delta^{-12}$ and $\Delta^{-6}$ fatty acid desaturase mutants (fat-2 and fat-3, respectively) completely lack this behaviour [5]. EPA (eicosapentaenoic acid; $\mathrm{C}_{20: 5, n-3}$ ) and AA are the main PUFAs in the wild-type strain, whereas neither EPA nor AA can be synthesized in the desaturase-deficient mutants. Concomitantly, only the wild-type, but not the fat-2 and fat-3 mutants, contain EPA- and AA-derived epoxy and hydroxy metabolites as produced by CYP monooxygenases when metabolizing these C20-PUFAs [17, 18]. We reported previously that also the EGL-9 deficient strain displayed very low levels of free CYP-eicosanoids and that this deficiency was partially overcome by the gain-of-function mutation in the cyp-13A12 gene [5].

Based on these findings, we hypothesised an essential role for C20-PUFA-derived CYPeicosanoids in mediating the O2-ON response and the locomotion behaviour of C. elegans. To address these questions, we cloned and heterologously co-expressed CYP-13A12 and EMB-8, analysed the substrate and reaction specificity of the recombinant monooxygenase system, and tested the effect of the major EPA-derived metabolite on the O2-ON response and locomotive activity of $C$. elegans. 


\section{EXPERIMENTAL}

\section{Nematode strain and cultivation condition}

The C. elegans wild-type strain Bristol N2 and the mutant strains fat-2(wa17), fat-3(ok1126) and fat-3(wa22) were used throughout this study. The nematodes were grown at $20^{\circ} \mathrm{C}$ on NGM (nematode growth medium) agar plates inoculated with Escherichia coli OP50 as food source [19] and were incubated under similar conditions as described before [17].

\section{Chemicals}

Non-labelled AA, EPA, ETYA (eicosatetraynoic acid), and 17,18-EEQ (17,18-epoxyeicosatetraenoic acid) were purchased from Cayman Chemicals; all radio-labelled fatty acids were purchased from Hartman Analytical GmbH. The compound used as 17,18-EEQ agonist was synthesized as described previously [20]. To prevent autooxidation, all stock solutions were prepared in an oxygen evacuated nitrogen chamber. DMSO (dimethyl sulfoxide), purchased from Sigma, was used as vehicle.

\section{Amplification and cloning of cyp-13A12 and emb-8 cDNAs}

To perform reverse transcription, $10 \mu \mathrm{g}$ total RNA, isolated from a C. elegans culture according to [21], was mixed with $0.8 \mu \mathrm{l}$ oligo dT and incubated for $5 \mathrm{~min}$ at $70^{\circ} \mathrm{C}$. Then, 3 $\mu \mathrm{l} 5 \mathrm{x}$ RT-buffer, $0.8 \mu \mathrm{l} 10 \mathrm{mM}$ dNTPs and, $0.4 \mu \mathrm{l}$ M-MLV revertase (Promega) were added and incubated for $90 \mathrm{~min}$ at $42{ }^{\circ} \mathrm{C}$. The reaction was stopped at $94{ }^{\circ} \mathrm{C}$ for $4 \mathrm{~min}$. Subsequently, PCR amplification of the cyp-13A12 and emb-8 cDNAs were performed using the Phusion ${ }^{\circledR}$ Flash PCR Mastermix (New England Biolabs) and the following primer pairs: 5'-TAGGCTTACACGGTCCGATC-ATGGCAATTATATTTCTTGC-3' and 5'-CAGAAGCTGCTCGAGTCAGTGATGAT-GGTGATGATTATCATCCCTCGGCGTC-3’ for cyp13A12 and 5'-ATGCGTAGTA-CGGTCCGATCATGCTGGCGTGGATTGTGTC-3' and 5'CTACGTTACCTCGAGTCAGTGATGATGATGATGGTGTGACCACACATCAGCTTGG3' for emb-8. Both reverse primers contained a $6 \times$ histidine encoding codon block directly in front of the stop codon to allow an immunological detection of all heterologously expressed proteins using a 6-histidine epitope tag antibody. The obtained cDNAs were cloned into the pFastBac $^{\mathrm{TM}} 1$ vector (Invitrogen), while RsrII and XhoI (New England Biolabs) were used as corresponding restriction enzymes. The identity of all cloned cDNAs was confirmed by full length sequencing of both DNA strands, performed by LGC Genomics.

\section{Generation of recombinant baculoviruses}

Recombinant baculoviruses containing the cloned cDNAs under control of the strong polyhedrin promoter were produced using the Bac-to-Bac ${ }^{\circledR}$ baculovirus expression system from Invitrogen. After re-amplification in Spodoptera frugiperda Sf9 cells, a virus titre of around $1-3 \times 10^{9}$ was obtained.

\section{cyp-13A12/emb-8 co-expression in insect cells and preparation of enzymatically active microsomes}

Sf9 cells were grown in Insectomed SF express medium (Biochrom) supplemented with 50 $\mathrm{U} / \mathrm{ml}$ penicillin, $50 \mu \mathrm{g} / \mathrm{ml}$ streptomycin, and $10 \%$ heat-inactivated foetal bovine serum. To generate a complete CYP-CPR monooxygenase system, Sf9 cultures were co-infected with recombinant baculoviruses of cyp-13A12 and C. elegans' CPR gene emb-8 after they reached a cell density of $2 \times 10^{6}$ cells/ml. Control groups were infected with an empty baculovirus or with either cyp-13A12 or emb-8 virus alone. Twenty-four h after infection, the Sf9 culture was supplemented with $5 \mu \mathrm{M}$ haemin chloride and $100 \mu \mathrm{M}$ riboflavin to support the production of CYP and CPR holoenzymes. The cells were harvested after $60 \mathrm{~h}$, resuspended in ice-cold 0.1 $\mathrm{M}$ potassium phosphate buffer, $\mathrm{pH}$ 7.4, containing $20 \%$ glycerol, $1 \mathrm{mM}$ EDTA, $100 \mu \mathrm{M}$ 
PMSF, and 0.5 mM DTT. The insect cells were homogenised by sonication three times for 20 s on ice. The microsomal fraction was prepared at $4{ }^{\circ} \mathrm{C}$ through differential centrifugation: 5 $\min$ at $3,000 \times \mathrm{g}, 20 \mathrm{~min}$ at $10,000 \times \mathrm{g}$ and $65 \mathrm{~min}$ at $100,000 \times \mathrm{g}$. Subsequently, the microsomes were resuspended and homogenized in $0.1 \mathrm{M}$ potassium phosphate buffer $\mathrm{pH} 7.4$ containing $20 \%$ glycerol, $1 \mathrm{mM}$ EDTA, and $0.5 \mathrm{mM}$ DTT. Several aliquots were shock frozen in liquid nitrogen and stored at $-80^{\circ} \mathrm{C}$.

The microsomal protein concentration was measured according to Lowry et al. [22]. The CYP content was determined by COD (carbon monoxide difference) spectra using a difference extinction coefficient of $91 \mathrm{mM}^{-1} \mathrm{~cm}^{-1}$ for the wavelength pair $450 \mathrm{~nm}$ minus 490 $\mathrm{nm}$ [23]. The CPR content was estimated as NADPH-cytochrome $c$ reductase activity using an extinction coefficient at $550 \mathrm{~nm}$ of $21 \mathrm{mM}^{-1} \mathrm{~cm}^{-1}$ [24].

\section{Western blot}

For Western blot analysis microsomal protein (3 $\mu$ g per lane) was separated by $10 \%$ sodium dodecyl sulphate-polyacrylamide gel electrophoresis and transferred to Immobilon-P PVDF membrane (Millipore) [25]. A polyclonal 6-histidine epitope tag antibody raised in rabbits (Novus Biologicals) was used as primary antibody against recombinant tagged CYP-13A12 and EMB-8, respectively. The peroxidase conjugated anti-rabbit secondary antibody was purchased from Sigma. The blots were developed with Amersham ECL prime Western blotting detection reagent and finally visualised by using Amersham Hyperfilm ${ }^{\text {TM }}$ ECL (GE Healthcare).

\section{Microsomal fatty acid metabolism}

[1- ${ }^{14} \mathrm{C}$-labelled AA $(53.8 \mathrm{mCi} / \mathrm{mmol})$ and EPA $(53.9 \mathrm{mCi} / \mathrm{mmol})$ (Hartman Analytical $\mathrm{GmbH}$ ) had radiochemical purities of $>99 \%$. To analyse the whole range of primary and secondary metabolites produced by CYP-13A12, reactions were performed in $400 \mu \mathrm{l} 0.1 \mathrm{mM}$ potassium phosphate buffer, $\mathrm{pH}$ 7.2, containing 50 pmol recombinant CYP-13A12 and the substrate at a final concentration of $10 \mu \mathrm{M}$. At first, the appropriate volume of microsomal sample was pre-incubated with the substrate for $10 \mathrm{~min}$ at $25^{\circ} \mathrm{C}$. Subsequently, the reaction was started with NADPH (1 mM final concentration) and terminated after 10 min shaking at $25{ }^{\circ} \mathrm{C}$ by adding $40 \mu \mathrm{l}$ of $0.4 \mathrm{M}$ citric acid on ice. The reaction products were extracted with ethyl acetate, evaporated under nitrogen and re-dissolved in $50 \mu \mathrm{l} 99.8 \%$ ethanol. Controls included omission of NADPH from the reaction mixtures and the use of microsomes lacking CYP-13A12 or EMB-8. The reactions were performed for each substrate at least in triplicate.

\section{Analysis of the metabolite profiles}

The reaction products formed from the $\left[1-{ }^{14} \mathrm{C}\right]$-labelled substrates were analysed by RP (reversed-phase)-HPLC (Shimadzu LC 10 Avp) using a Nucleosil 100-5C18HD column (250 $\times 4 \mathrm{~mm}$; Macherey-Nagel, Germany) and a linear solvent gradient of acetonitrile/water/acetic acid (50:50:0.1, v/v/v) to acetonitrile/acetic acid (100:0.1, v/v) over $45 \mathrm{~min}$ at a flow rate of 1 $\mathrm{ml} / \mathrm{min}$. For detection and quantification of the metabolites, an online radio flow detector (LB 509; Berthold) was used. Authentic standard compounds were prepared and used as described previously [26, 27]. The AA and EPA hydroxylase activities were derived from the sum of 19-/20-HETE (19-/20-hydroxyeicosatetraenoic acid) and 19-/20-HEPE (19-/20hydroxyeicosapentaenoic acid), respectively, and total AA and EPA epoxygenase activities as the sum of all detectable EETs (epoxyeicosatrienoic acids) and EEQs, respectively. All data were calculated per minute and nmol of CYP protein, as determined by the corresponding COD. The metabolite profiles were also analysed by LC-MS/MS (liquid chromatographymass spectrometry) using a triple quadrupole tandem mass spectrometer Agilent 6460 combined with an Agilent 1200 HPLC-system as described before [28]. For these 
experiments, microsomal incubations were performed exactly as described above; however, unlabelled AA and EPA were used as substrates.

\section{Preparation of assay plates and treatment}

For long-term incubations, C20-PUFA stocks were mixed with living OP50 bacteria and seeded on NGM plates at a final concentration of $80 \mu \mathrm{mol}$ in the bacterial lawn. Plates were dried in the dark at room temperature. Worms from a mixed culture were chunked to assay plates and incubated for a couple of days to ensure that next generation was fed its whole life with dietary PUFA. Then, age-synchronised nematodes were obtained by bleaching gravid nematodes disintegrating all worms but eggs [29]. This synchronised progeny was incubated on freshly supplemented NGM/OP50 agar plates for three further days prior use in the locomotion assay. Vehicle control experiments were included by mixing only solvent, $0.3 \%$ (v/v) DMSO, with the bacteria. Only in case of the multi-worm tracker experiments, C20PUFA salts were dissolved in ethanol at $1 \mathrm{mg} / \mathrm{ml}$ and $50 \mu 1$ were spread evenly onto NGM plates before drying briefly and cultivating E. coli OP50 on the plates.

For short-term incubations, two synchronized young adults ( $>15$ trials per strain) were spread onto NGM/OP50 plates supplemented with either $10 \mu \mathrm{M}$ of EPA, 17,18-EEQ, a 17,18EEQ agonist, or only $0.3 \%(\mathrm{v} / \mathrm{v})$ DMSO as vehicle control. In this case, time of treatment was limited to $40 \mathrm{~min}$.

\section{Locomotive behaviour}

The locomotive behaviour was measured by two different methods based on experience and equipment of the involved laboratories. The O2-ON response of young adult fat-2(wa17) ( $n>50$ for each treatment) was continuously measured using a multi-worm tracker with a gasflow chamber system and quantified by customized MatLab algorithms as previously described [4]. For characterizing the locomotive behaviour of wild-type and fat-3(wa22), we determined the worm's speed and body bend frequency according to Hart, 2006 [30]. At least thirty worms per treatment were examined for each replicate by using a VHX-600 digital microscope (Keyence). To determine the move length, two nematodes per trial were transferred to a fresh plate and the length of a 20 s crawler lane leaved in the OP50 lawn was measured for each individual. In addition, body bends as change in the direction of C. elegans movement were counted. A binocular capable, custom built acrylic glass chamber equipped with an oxygen manometer (DO-100 from Voltcraft) and a gas-flow system of pure $\mathrm{N}_{2}$ was used for experiments involving anoxia condition. Reoxygenation was achieved by setting open plates back to ambient air for 2 min.

\section{Determination of the endogenous EPA and 17,18-EEQ content}

The amount of free EPA and the CYP-derived metabolite 17,18-EEQ was determined by LCMS/MS for the wild-type under normoxia, anoxia (5 min) and reoxygenation (2 min) conditions. To ensure anoxia conditions during the process of harvest as long as possible, liquid nitrogen was carefully filled at the bottom of the anoxia chamber, but without freezing the agar inside the Petri dishes. Then, nematodes were washed with ice-cold M9 buffer from the plates and prepared for LC-MS/MS analysis essentially as described previously [17, 18].

\section{Statistical analysis}

The locomotion assay and the endogenous EPA and 17,18-EEQ datasets were analysed by one way analysis of variance to test for significant differences between treatments followed by the Bonferroni test to identify treatments that were significantly different from the control. All statistical tests were performed using Sigma Stat 3.5 (Systat Software, Inc., USA). The error bars in the figures represent standard deviations. 


\section{RESULTS}

\section{Cloning and heterologous expression of cyp-13A12 and emb-8}

The coding sequences of $e m b-8$ and cyp-13A12 were amplified from C. elegans N2 and showed $100 \%$ identity with the corresponding mRNA sequences (NM_065702.5 and NM_067304.3) as available from NCBI Nucleotide. Heterologous expression of both components was successfully achieved in a baculovirus/Sf9 insect cell system. Microsomes isolated from insect cells transfected with the recombinant cyp-13A12 baculovirus displayed reduced carbon monoxide difference spectra as characteristic for P450 proteins (Fig. 1A). The Soret peak at $450 \mathrm{~nm}$ indicated that the majority of the recombinant CYP protein retained the haem-thiolate co-ordination in the ferrous-CO complex. Only a very small amount of a P420 form, which could reveal an inactive form of the enzyme, was detectable. A maximal expression level of $0.59 \mathrm{nmol}$ CYP-13A12 per mg microsomal protein was obtained $60 \mathrm{~h}$ after infection. Control microsomes, isolated after transfection with an empty baculovirus, were free of any spectrally detectable CYP protein (data not shown). Microsomes containing recombinant EMB-8 showed NADPH-dependent reduction of cytochrome $c$ with a reductase activity of $43.3 \mathrm{mU} / \mathrm{mg}$ protein.

For metabolic studies, the required co-expression of cyp-13A12 with emb-8 was achieved by co-infection of Sf9 cells with both recombinant baculoviruses. The microsomes obtained from these co-infected cells contained $0.34 \mathrm{nmol}$ spectrally active CYP-13A12/mg protein and 53.1 $\mathrm{mU}$ EMB-8/mg protein. Successful co-expression of both the His-tagged recombinant CYP13A12 and EMB-8 was also confirmed by Western blotting. The expression of both components became visible $48 \mathrm{~h}$ post infection and reached a maximum after $60 \mathrm{~h}$ (Fig. 1B). The samples showed the presence of a prominent $58 \mathrm{kDa}$ protein band for CYP-13A12 and a band at $79 \mathrm{kDa}$ for EMB-8, both enriched in the microsomal fraction (Fig. 1B).

\section{Metabolism of AA by recombinant CYP-13A12/EMB-8}

The recombinant microsomal CYP-13A12/EMB-8 system metabolised AA to a complex product pattern predominantly consisting of epoxy and hydroxy metabolites (Fig. 2A). AA was metabolized only in the presence of NADPH and none of the metabolites occurred in incubations with control microsomes lacking CYP-13A12 or EMB-8. The main primary epoxy metabolite produced by CYP-13A12 was 14,15-EET, followed by 11,12-EET. The main primary hydroxy metabolites produced by CYP-13A12 co-migrated with 19-/20-HETE. A group of minor reaction products eluted in the RP-HPLC between 19-/20-HETE and 14,15EET indicating the formation monohydroxy derivatives originating from CYP-13A12catalysed mid-chain oxidations.

LC-MS/MS analysis was used to validate the identity of the obtained metabolites (Fig. 2B). The primary epoxy products were confirmed as 14,15-EET (47.4\% of total products) and 11,12-EET (13.9 \% of total products). In addition, low amounts of 8,9-EET (1.0 \% of total products) were detectable. 19-HETE (24.5\% of total products) was identified as the main primary monohydroxy product. In addition, minor amounts of 15-HETE, 12-HETE and 11HETE (together $4.2 \%$ of total products), but none of the other potential mid-chain HETEs were produced (Fig. 2B). The ratio of epoxy to monohydroxy products was about 2:1. Moreover, small amounts of 14,15- and 11,12-HEET (hydroxyepoxyeicosatrienoic acid) were detectable that were presumably formed as secondary metabolites, e.g. by secondary $\omega$ hydroxylation of the primary EETs. At a substrate concentration of $10 \mu \mathrm{M}$, AA was metabolized by the CYP-13A12/EMB-8 monooxygenase system with a rate of 0.43 $\mathrm{nmol} / \mathrm{nmol} / \mathrm{min}$ to the primary epoxy metabolites and with a rate of $0.26 \mathrm{nmol} / \mathrm{nmol} / \mathrm{min}$ to primary hydroxy metabolites. 


\section{Metabolism of EPA by recombinant CYP-13A12/EMB-8}

The CYP-13A12/EMB-8 system accepted also EPA as substrate and converted this $n-3$ PUFA to a set of epoxy as well as monohydroxy metabolites. 17,18-EEQ represented the main primary epoxy metabolite, whereas the main primary monohydroxy product co-migrated with 19-/20-HEPE (Fig. 2C). No product formation occurred in control experiments, when either NADPH was omitted or microsomes lacking CYP-13A12 or EMB-8 were used.

The identities of the EPA metabolites produced by CYP-13A12 were also confirmed by LCMS/MS analysis (Fig. 2D). The main primary epoxy products were identified as 17,18-EEQ (64.5\% of total product) and 11,12-EEQ (10.7\% of total product); Fig. 2D. Including also 14,15-EEQ and 8,9-EEQ, the epoxy metabolites represented together $89.2 \%$ of total products. As the main primary monohydroxy product, 18-HEPE was about $2.4 \%$ of total products; 20 -, 19-, 15-, 12-, 9-, 8- and 5-HEPE represented together about 5.6\% of total products (Fig. 2D). The ratio of epoxy and monohydroxy metabolites was about 11:1. In addition, 17,18-DiHETE (17,18-dihydroxyeicosatetraenoic acid) originating from the hydrolysis of 17,18-EEQ was present in minor amounts (2.1\% of total product). Formation of total primary metabolites from EPA occurred with a rate of $0.45 \mathrm{nmol} / \mathrm{nmol} / \mathrm{min}$ for epoxy metabolites and 0.06 $\mathrm{nmol} / \mathrm{nmol} / \mathrm{min}$ for hydroxy metabolites.

\section{A C20-PUFA-metabolite is required for the normal $\mathrm{O2-ON}$ response}

In line with previous studies [5], the O2-ON response was well pronounced in the C. elegans N2 wild-type strain, but did not occur in the C20-PUFA-deficient fat-2(wa17) and fat3(ok1126) mutants (Figs. 3A-C). As shown for the fat-2(wa17) mutant, this phenotypic impairment was rescued after feeding the worms AA or EPA for several days using the longterm incubation protocol with $80 \mu \mathrm{M}$ C20-PUFAs as described in the Experimental section (Figs. 3D and 3E). In contrast, ETYA, a non-metabolisable AA-analogue, failed to restore the O2-ON response under otherwise identical conditions (Fig. 3F).

The normal O2-ON response of the wild-type strain (Fig. 4A) was accompanied by significant changes in the endogenous levels of free EPA (Fig. 4C) and its CYP-dependent metabolite 17,18-EEQ (Fig. 4 D) as revealed by LC-MS/MS analysis of worms harvested during normoxia, 5 min after anoxia, and 2 min after reoxygenation. Free EPA levels were already slightly higher after anoxia compared to normoxia and then increased almost 5-fold in the immediate reoxygenation phase. Free 17,18-EEQ levels declined during anoxia and were then rapidly restored in response to reoxygenation. Similar, but less pronounced, changes were observed regarding the release of free AA and the formation of its CYP-dependent metabolite 14,15-EET. However, the maximal levels of free AA and 14,15-EET reached only about 30 and $10 \%$ of the corresponding EPA and 17,18-EEQ levels (data not shown).

To test the hypothesis that 17,18-EEQ is required for the O2-ON response, we pre-treated worms carrying the fat-3(wa22) mutation with this EPA-derived epoxy metabolite. In the presence of $10 \mu \mathrm{M}$ 17,18-EEQ, we observed an almost two-fold increase of the nematode's speed and number of body bends after a $5 \mathrm{~min} / 2 \mathrm{~min}$ anoxia/reoxygenation event, compared to the non-treated control group (Fig. 4B, right panel). However, the exogenously applied 17,18-EEQ was already effective during normoxia (Fig. 4B, left panel), indicating that 17,18EEQ has the capacity of increasing the locomotion speed also independent of anoxia/reoxygenation as shown in detail below.

\section{7,18-EEQ increases the locomotive activity of $C$. elegans}


In the last part of this study, we compared the effects of C20-PUFA- and 17,18-EEQsupplementation on the locomotion behaviour of the fat-3(wa22) mutant and N2 wild-type strains; the chemical structures of compounds used for treatment are shown in Fig. 5A. In these experiments, we took advantage of the fact that C20-PUFA deficiency does not only abolish the O2-ON response, but already impairs locomotion under normoxic conditions. Compared to their wild-type counterparts, untreated fat-3(wa22) worms showed an almost 50 $\%$ reduction of migration speed and number of body bends per min when kept on agar plates in ambient air (Fig. $5 \mathrm{~B}$ and C, left panels). The impaired locomotion behaviour of the C20PUFA-deficient fat-3(wa22) mutant strain was largely improved upon long-term incubation (3 d, $80 \mu \mathrm{M}$ ) with exogenous EPA or AA (Fig. 5B, central panel). In contrast, neither EPA- nor AA-supplementation increased the normal locomotion activity of the N2 wild-type strain that is self-sufficient in producing C20-PUFAs (Fig. 5C, central panel). ETYA, the nonmetabolisable AA analogue, significantly reduced the speed and body bending of wild-type worms, but did neither rescue nor further decrease the impaired locomotion activity of the fat3(wa22) mutant strain (Fig. 5 B and C, left panels).

17,18-EEQ clearly rescued the fat-3(wa22) mutant strain from locomotion impairment already when administered for $40 \mathrm{~min}$ at a concentration of $10 \mu \mathrm{M}$ (Fig. 5B, right panel). In contrast, the same treatment regime was not sufficient for achieving any effects with EPA, the precursor of 17,18-EEQ. Remarkably, however, the short-term exposure to 17,18-EEQ was almost as effective as long-term EPA or AA feeding. Like 17,18-EEQ, a synthetic 17,18-EEQ agonist also accelerated the migration of the worms (Fig. 5B, right panel). Complementing studies with the N2 strain revealed that also wild-type worms respond with increased locomotion activity when exposed to 17,18-EEQ or its synthetic agonist (Fig. 5C, right panel).

\section{DISCUSSION}

The present study demonstrates that CYP-13A12 and EMB-8 constitute a microsomal monooxygenase system that metabolizes C20-PUFAs and, thereby, generates signalling molecules regulating the locomotion behaviour of $C$. elegans. The identity of the monooxygenase system and its function are in line with and directly explain previous genetic data implicating the cyp-13A12 and $e m b-8$ genes as well as C20-PUFAs into the O2-ON response of C. elegans [5].

The recombinant CYP13A12/EMB8 monooxygenase system functioned predominantly as an epoxygenase when metabolizing AA and EPA. The main product produced from AA was 14,15-EET, whereas EPA was preferentially epoxidised at its $(\omega-3)$ double bond to yield 17,18 -EEQ as the main metabolite. Moreover, CYP-13A12 showed ( $\omega$ - 1 )-hydroxylase activity with AA, and also catalysed mid-chain oxidations resulting in a series of regioisomeric hydroxy metabolites as minor products. The metabolite patterns of CYP-13A12 resemble those produced by CYP-33E2 from C. elegans [18], CYP2J2, an epoxygenase highly expressed in the human heart [31, 32], and also human CYP3A4 [14]. CYP-13A12, CYP-33E2 and CYP2J2 have in common that they prefer EPA over AA as substrate and show a regioselectivity in favour of 17,18-EEQ as the main EPA-derived metabolite. Compared with CYP-13A12, CYP3A4 displays a lower regioselectivity and produces considerably higher amounts of various mid-chain oxidation products [33]. Among the human counterparts of CYP-13A12, CYP2J2 has attracted particular interest for its protective role in ischemia/reperfusion injury. CYP2J2 overexpression in transgenic mice mediates improved postischemic functional recovery of the heart and reduces infarction size [34, 35]. CYP2J2 overexpression also protects against hypoxia-reoxygenation injury in cultured endothelial 
cells [36]. Most recently, CYP2J2 was shown to exert marked neuroprotective effects in a mouse model of cerebral ischemia [37].

EPA and AA are the main C20-PUFAs in C. elegans, whereby EPA represents about $30 \%$ and AA about $5 \%$ of total fatty acids [17]. As exemplified in the present study by the fat-2 and fat-3 mutant strains, any inability of synthesising C20-PUFAs is associated with impaired locomotion activity already under normoxic conditions and a lack of the O2-ON response to anoxia/reoxygenation. Long-term feeding with EPA or AA, but not with ETYA, rescued this impaired locomotion behaviour. ETYA harbours triple instead of double bonds [38] and has been used as a non-metabolisable analogue of AA and inhibitor of AA-derived eicosanoid formation [39-41]. Noteworthy, C20-PUFAs are also essential for touch sensation of $C$. elegans. Unlike impaired locomotion, this phenotype can be rescued both by AA and its nonmetabolisable analogue ETYA [42]. These findings suggested that C20-PUFAs modulate touch sensation while being incorporated into membrane phospholipids [42], whereas EPAand AA-derived metabolites, rather than the parental C20-PUFAs themselves, regulate the locomotion activity of the nematodes.

Indeed, our subsequent experiments revealed that 17,18-EEQ, the major EPA-derived metabolite produced by the CYP-13A12/EMB-8 monooxygenase system, was alone sufficient to improve the impaired locomotion activity of the C20-PUFA deficient fat-3(wa22) strain. This effect occurred already after short-term exposure of the worms to $10 \mu \mathrm{M} 17,18$-EEQ, whereas long-term feeding and much higher concentrations were required to achieve similar effects with AA or EPA. Also other authors found that high concentrations and a minimal time of about $24 \mathrm{~h}$ are required to restore the phenotype of fat-3 mutants by C20-PUFA supplementation [43-48]. Remarkably, the exogenously administered 17,18-EEQ increased the locomotion activity already under normoxic conditions and was effective not only with the mutant but to a lesser extent also with wild-type worms. According to our LC-MS/MS data, 17,18-EEQ is also the leading candidate for mediating the O2-ON response of the wild-type strain. These data show that free 17,18-EEQ levels decline during anoxia and are rapidly restored upon reoxygenation. Providing the substrate for increased de novo biosynthesis of 17,18-EEQ, free EPA levels were strongly increased upon anoxia/reoxygenation. Taken together, these results suggest a direct correlation between the free 17,18-EEQ levels and the locomotive activity of $C$. elegans. This correlation also explains that exogenous 17,18-EEQ was already effective under normoxic conditions, whereas the O2-ON response is obviously mediated by enhanced endogenous 17,18-EEQ biosynthesis following anoxia/reoxygenation. We cannot exclude the possibility that other EPA- and also AA-derived metabolites share the locomotion-promoting capacity of 17,18-EEQ. In particular, AA-derived metabolites such as 14,15-EET may take over the function of 17,18-EEQ, if EPA is not available as suggested by the normal locomotion behaviour of fat- 1 mutants that are unable to synthesise $n-3$ PUFAs [49]. Moreover, considering that the substrate and reaction specificities of CYP-13A12 and CYP-33E2 largely overlap, further genetic analysis is required to dissect the individual roles of these enzymes in the $\mathrm{O} 2-\mathrm{ON}$ response.

The postulated role of 17,18-EEQ as a mediator of the O2-ON response in C. elegans (compare Fig. 6) is in line with the general concept of CYP-eicosanoid formation and action as established in mammalian cells [50-53]. CYP enzymes require molecular oxygen, NADPH, and free C20-PUFAs to catalyse epoxidation and hydroxylation reactions [54]. Accordingly, the biosynthesis of epoxy and hydroxy metabolites proceeds under normoxic conditions and is limited by the availability of free EPA and AA as substrates. Under basal conditions, the majority of intracellular EPA and AA are esterified into membrane phospholipids. Thus, de novo synthesis of CYP-eicosanoids is in general strictly coupled to the activation of 
phospholipases as triggered by diverse hormones and growth factors [51]. Importantly, also hypoxia results in phospholipase activation and thus provides free C20-PUFAs for CYPdependent metabolite formation in the subsequent reoxygenation phase. In mammalian cells, ischemia activates the cytosolic calcium-dependent phospholipase A2 that liberates AA and other PUFAs from the sn-2 position of glycerophospholipids [55-57]; however, the identity and substrate specificity of the phospholipases activated in the nematode during anoxia/reoxygenation remain to be elucidated. Once produced, the epoxides of C20-PUFAs can be rapidly further metabolised and inactivated by soluble epoxide hydrolases [58]. $C$. elegans harbours two genes encoding soluble epoxide hydrolases [59]; however, their role in modulating the locomotive activity remains to be shown.

The cellular and molecular mechanisms of how 17,18-EEQ increases the locomotive activity of C. elegans are unknown. In mammals, CYP-eicosanoids act in an autocrine or paracrine manner and serve as second messengers of diverse hormones regulating the contractility of vascular smooth muscle cells and cardiomyoctes [20, 60, 61]. In C. elegans, 17,18-EEQ mediates the O2-ON response by increasing the activity of body muscle cells. Surprisingly, we found that CYP-13A12 and also CYP-33E2, another 17,18-EEQ-generating CYP isoform, are predominantly located in the MCs (marginal cells) of the worm's pharynx $[5,18]$. MCs intercalate with pharyngeal muscles and might, on the one hand, structurally reinforce these muscles [62]. On the other hand, MCs contain abundant mitochondria, suggesting that these cells might perform active non-structural roles [63], too. Nonetheless, it is currently largely unclear how CYP-eicosanoids produced in the pharynx are able to modulate the muscle activity in the worm's body. Possibly, 17,18-EEQ is secreted by the marginal cells and then recognized as a signalling molecule by nearby sensory neurons that in turn trigger the O2-ON response via neural circuits $[64,65]$ known to control forward/backward locomotion. Within this process, 17,18-EEQ might also stimulate the release of neuropeptides that act as neurohormones onto body muscles. Providing a first link between C20-PUFA deficiency and neurotransmission, fat-3(lg8101) worms were shown to release abnormally low levels of neurotransmitters at cholinergic and serotonergic neuromuscular junctions and to be depleted of synaptic vesicles [43].

The O2-ON response of $C$. elegans and ischemia/reperfusion injury of mammalian organs are quite different in terms of their final outcomes. However, as elaborated in the present study, they may share common mechanisms of CYP-eicosanoid formation and action. In particular, it appears that the epoxy metabolites, known to play a protective role in ischemia reperfusion injury, serve in C. elegans as mediators of the O2-ON response. A major open question concerning both research fields is the identity of the primary cellular targets of CYPeicosanoids. Increasing evidence obtained in mammalian systems suggests the existence of GPCRs (G protein-coupled receptors) that specifically interact with selected sets of epoxy and hydroxy metabolites derived from $n-6$ and n-3 PUFAs [52, 66, 67]. Supporting the hypothesis that 17,18-EEQ may interact with similar targets in mammals and $C$. elegans, we found that a metabolically robust synthetic analogue, developed to mimic the effect of 17,18 EEQ on cardiomyocyte contractility [20], was also effective in modulating the locomotive activity of $C$. elegans. Further genetic analysis of the components mediating the 17,18-EEQ effects in C. elegans may facilitate the search for the thus far unknown receptors of CYPeicosanoids.

\section{ACKNOWLEDGEMENTS}

We thank the Caenorhabditis Genetics Centre (CGC), which is funded by the National Institutes of Health National Centre for Research Resources, for the supply of N2, fat- 
2(wa17), and fat-3(wa22). We are grateful to Christel Andrée and Ramona Zummach (both MDC, Germany) for excellent technical support and advice during the in vitro assays and the HPLC experiments. We would also like to thank Dr. Michael Rothe (Lipodomix GmbH, Germany) for performing the identification and quantification of PUFA derived epoxy and hydroxy metabolites. Finally, we thank Yiwen Zhou (HU Berlin, Germany) for providing assistance with conditions of eicosanoid exposure.

\section{FUNDING}

W.H.S. and R.M. were supported by grants from the German Research Foundation (DFG), SCHU 822/5-2 and ME 2056/3-1, respectively. J.R.F. was supported by the Robert A. Welch Foundation (GL625910) and USPHS NIH (DK38226).

\section{AUTHOR CONTRIBUTIONS}

R.M. and W.-H.S. designed the study; A.E. and J.K. performed heterologous expression and metabolism experiments, A.K. supervised this experimental work; D.M., J.J. and E.N. performed the locomotion assays; J.F. performed the chemical synthesis of the 17,18-EEQ agonist. R.M., J.K., and W.-H.S. wrote the manuscript, J.F. and A.K. performed proofreading.

\section{REFERENCES}

1 Eltzschig, H. K. and Eckle, T. (2011) Ischemia and reperfusion - from mechanism to translation. Nat. Med. 17, 1391-1401

2 Chang, A. J., Chronis, N., Karow, D. S., Marletta, M. A. and Bargmann, C. I. (2006) A distributed chemosensory circuit for oxygen preference in C. elegans. PLoS Biol. 4, e274

3 Ma, D. K. and Ringstad, N. (2012) The neurobiology of sensing respiratory gases for the control of animal behavior. Front Biol. 7, 246-253

4 Ma, D. K., Vozdek, R., Bhatla, N. and Horvitz, H. R. (2012) CYSL-1 interacts with the $\mathrm{O}_{2}$-sensing hydroxylase EGL-9 to promote $\mathrm{H}_{2} \mathrm{~S}$-modulated hypoxia-induced behavioral plasticity in C. elegans. Neuron. 73, 925-940

5 Ma, D. K., Rothe, M., Zheng, S., Bhatla, N., Pender, C. L., Menzel, R. and Horvitz, H. R. (2013) Cytochrome P450 drives a HIF-regulated behavioral response to reoxygenation by $C$. elegans. Science. 341, 554-558

6 Epstein, A. C., Gleadle, J. M., McNeill, L. A., Hewitson, K. S., O'Rourke, J., Mole, D. R., Mukherji, M., Metzen, E., Wilson, M. I., Dhanda, A., Tian, Y. M., Masson, N., Hamilton, D. L., Jaakkola, P., Barstead, R., Hodgkin, J., Maxwell, P. H., Pugh, C. W., Schofield, C. J. and Ratcliffe, P. J. (2001) C. elegans EGL-9 and mammalian homologs define a family of dioxygenases that regulate HIF by prolyl hydroxylation. Cell. 107, 43-54

7 Kaelin, W. G., Jr. and Ratcliffe, P. J. (2008) Oxygen sensing by metazoans: the central role of the HIF hydroxylase pathway. Mol. Cell. 30, 393-402

8 Desai, C. and Horvitz, H. R. (1989) Caenorhabditis elegans mutants defective in the functioning of the motor neurons responsible for egg laying. Genetics. 121, 703-721

9 Semenza, G. L. (2012) Hypoxia-inducible factors in physiology and medicine. Cell. 148, 399-408

10 Powell-Coffman, J. A. (2010) Hypoxia signaling and resistance in C. elegans. Trends Endocrinol. Metab. 21, 435-440 
11 Gotoh, O. (1998) Divergent structures of Caenorhabditis elegans cytochrome P450 genes suggest the frequent loss and gain of introns during the evolution of nematodes. Mol. Biol. Evol. 15, 1447-1459

12 Booth Depaz, I. M., Toselli, F., Wilce, P. A. and Gillam, E. M. (2013) Differential expression of human cytochrome P450 enzymes from the CYP3A subfamily in the brains of alcoholic subjects and drug-free controls. Drug Metab. Dispos. 41, 1187-1194

13 Ghosh, C., Marchi, N., Desai, N. K., Puvenna, V., Hossain, M., Gonzalez-Martinez, J., Alexopoulos, A. V. and Janigro, D. (2011) Cellular localization and functional significance of CYP3A4 in the human epileptic brain. Epilepsia. 52, 562-571

14 Ayajiki, K., Fujioka, H., Toda, N., Okada, S., Minamiyama, Y., Imaoka, S., Funae, Y., Watanabe, S., Nakamura, A. and Okamura, T. (2003) Mediation of arachidonic acid metabolite(s) produced by endothelial cytochrome P-450 3A4 in monkey arterial relaxation. Hypertens. Res. 26, 237-243

15 Pratt-Hyatt, M., Zhang, H., Snider, N. T. and Hollenberg, P. F. (2010) Effects of a commonly occurring genetic polymorphism of human CYP3A4 (I118V) on the metabolism of anandamide. Drug Metab. Dispos. 38, 2075-2082

16 Rappleye, C. A., Tagawa, A., Le Bot, N., Ahringer, J. and Aroian, R. V. (2003) Involvement of fatty acid pathways and cortical interaction of the pronuclear complex in Caenorhabditis elegans embryonic polarity. BMC Dev. Biol. 3, 8

17 Kulas, J., Schmidt, C., Rothe, M., Schunck, W. H. and Menzel, R. (2008) Cytochrome P450-dependent metabolism of eicosapentaenoic acid in the nematode Caenorhabditis elegans. Arch. Biochem. Biophys. 472, 65-75

18 Kosel, M., Wild, W., Bell, A., Rothe, M., Lindschau, C., Steinberg, C. E. W., Schunck, W. H. and Menzel, R. (2011) Eicosanoid formation by a cytochrome P450 isoform expressed in the pharynx of Caenorhabditis elegans. Biochem. J. 435, 689-700

19 Brenner, S. (1974) The genetics of Caenorhabditis elegans. Genetics. 77, 71-94

20 Falck, J. R., Wallukat, G., Puli, N., Goli, M., Arnold, C., Konkel, A., Rothe, M., Fischer, R., Muller, D. N. and Schunck, W. H. (2011) 17(R),18(S)epoxyeicosatetraenoic acid, a potent eicosapentaenoic acid (EPA) derived regulator of cardiomyocyte contraction: Structure-activity relationships and stable analogues. J. Med. Chem. 54, 4109-4118

21 Menzel, R., Rödel, M., Kulas, J. and Steinberg, C. E. W. (2005) CYP35: xenobiotically induced gene expression in the nematode Caenorhabditis elegans. Arch. Biochem. Biophys. 438, 93-102

22 Lowry, O. H., Rosebrough, N. J., Farr, A. L. and Randall, R. J. (1951) Protein measurement with the Folin phenol reagent. J. Biol. Chem. 193, 265-275

23 Omura, T. and Sato, R. (1964) The Carbon Monoxide-Binding Pigment of Liver Microsomes. Ii. Solubilization, Purification, and Properties. J. Biol. Chem. 239, 23792385

24 Yasukochi, Y. and Masters, B. S. (1976) Some properties of a detergent-solubilized NADPH-cytochrome c(cytochrome P-450) reductase purified by biospecific affinity chromatography. J. Biol. Chem. 251, 5337-5344

25 Laemmli, U. K. (1970) Cleavage of structural proteins during the assembly of the head of bacteriophage T4. Nature. 227, 680-685

26 Arnold, C., Markovic, M., Blossey, K., Wallukat, G., Fischer, R., Dechend, R., Konkel, A., von Schacky, C., Luft, F. C., Muller, D. N., Rothe, M. and Schunck, W. H. (2010) Arachidonic acid-metabolizing cytochrome P450 enzymes are targets of \{omega -3 fatty acids. J. Biol. Chem. 285, 32720-32733

27 Barbosa-Sicard, E., Markovic, M., Honeck, H., Christ, B., Muller, D. N. and Schunck, W. H. (2005) Eicosapentaenoic acid metabolism by cytochrome P450 enzymes of the CYP2C subfamily. Biochem. Biophys. Res. Commun. 329, 1275-1281 
28 Fischer, R., Konkel, A., Mehling, H., Blossey, K., Gapelyuk, A., Wessel, N., von Schacky, C., Dechend, R., Muller, D. N., Rothe, M., Luft, F. C., Weylandt, K. and Schunck, W. H. (2014) Dietary omega-3 fatty acids modulate the eicosanoid profile in man primarily via the CYP-epoxygenase pathway. J. Lipid Res. 55, 1150-1164

29 Lewis, J. A. and Fleming, J. T. (1995) Basic culture methods. Methods Cell Biol. 48, 329

30 Hart, A. (2006) Behavior. In WormBook (The C. elegans Research Community, eds.)

31 Wu, S., Moomaw, C. R., Tomer, K. B., Falck, J. R. and Zeldin, D. C. (1996) Molecular cloning and expression of CYP2J2, a human cytochrome P450 arachidonic acid epoxygenase highly expressed in heart. J. Biol. Chem. 271, 3460-3468

32 Fer, M., Dreano, Y., Lucas, D., Corcos, L., Salaun, J. P., Berthou, F. and Amet, Y. (2008) Metabolism of eicosapentaenoic and docosahexaenoic acids by recombinant human cytochromes P450. Arch. Biochem. Biophys. 471, 116-125

33 Bylund, J., Kunz, T., Valmsen, K. and Oliw, E. H. (1998) Cytochromes P450 with bisallylic hydroxylation activity on arachidonic and linoleic acids studied with human recombinant enzymes and with human and rat liver microsomes. J. Pharmacol. Exp. Ther. 284, 51-60

34 Seubert, J., Yang, B., Bradbury, J. A., Graves, J., Degraff, L. M., Gabel, S., Gooch, R., Foley, J., Newman, J., Mao, L., Rockman, H. A., Hammock, B. D., Murphy, E. and Zeldin, D. C. (2004) Enhanced postischemic functional recovery in CYP2J2 transgenic hearts involves mitochondrial ATP-sensitive K+ channels and p42/p44 MAPK pathway. Circ. Res. 95, 506-514

35 Edin, M. L., Wang, Z., Bradbury, J. A., Graves, J. P., Lih, F. B., DeGraff, L. M., Foley, J. F., Torphy, R., Ronnekleiv, O. K., Tomer, K. B., Lee, C. R. and Zeldin, D. C. (2011) Endothelial expression of human cytochrome P450 epoxygenase CYP2C8 increases susceptibility to ischemia-reperfusion injury in isolated mouse heart. FASEB J. 25, 3436-3447

36 Yang, B., Graham, L., Dikalov, S., Mason, R. P., Falck, J. R., Liao, J. K. and Zeldin, D. C. (2001) Overexpression of cytochrome P450 CYP2J2 protects against hypoxiareoxygenation injury in cultured bovine aortic endothelial cells. Mol. Pharmacol. 60, 310-320

37 Li, R., Xu, X. Z., Chen, C., Yu, X. F., Edin, M. L., Degraff, L. M., Lee, C. R., Zeldin, D. C. and Wang, D. W. (2012) Cytochrome P450 2J2 is protective against global cerebral ischemia in transgenic mice. Prostaglandins Other Lipid Mediat. 99, 68-78

38 Tobias, L. D. and Hamilton, J. G. (1979) The effect of 5,8,11,14-eicosatetraynoic acid on lipid metabolism. Lipids. 14, 181-193

39 Morisaki, N., Lindsey, J. A., Stitts, J. M., Zhang, H. and Cornwell, D. G. (1984) Fatty acid metabolism and cell proliferation. V. Evaluation of pathways for the generation of lipid peroxides. Lipids. 19, 381-394

40 Harris, R. C., Munger, K. A., Badr, K. F. and Takahashi, K. (1990) Mediation of renal vascular effects of epidermal growth factor by arachidonate metabolites. FASEB J. 4, 1654-1660

41 McGiff, J. C. (1991) Cytochrome P-450 metabolism of arachidonic acid. Annu. Rev. Pharmacol. Toxicol. 31, 339-369

42 Vasquez, V., Krieg, M., Lockhead, D. and Goodman, M. B. (2014) Phospholipids that contain polyunsaturated fatty acids enhance neuronal cell mechanics and touch sensation. Cell Rep. 6, 1-11

43 Lesa, G. M., Palfreyman, M., Hall, D. H., Clandinin, M. T., Rudolph, C., Jorgensen, E. M. and Schiavo, G. (2003) Long chain polyunsaturated fatty acids are required for efficient neurotransmission in C. elegans. J. Cell Sci. 116, 4965-4975 
44 Watts, J. L., Phillips, E., Griffing, K. R. and Browse, J. (2003) Deficiencies in C20 polyunsaturated fatty acids cause behavioral and developmental defects in Caenorhabditis elegans fat-3 mutants. Genetics. 163, 581-589

45 Kahn-Kirby, A. H., Dantzker, J. L., Apicella, A. J., Schafer, W. R., Browse, J., Bargmann, C. I. and Watts, J. L. (2004) Specific polyunsaturated fatty acids drive TRPV-dependent sensory signaling in vivo. Cell. 119, 889-900

46 Taubert, S., Van Gilst, M. R., Hansen, M. and Yamamoto, K. R. (2006) A mediator subunit, MDT-15, integrates regulation of fatty acid metabolism by NHR-49-dependent and -independent pathways in C. elegans. Genes Dev. 20, 1137-1149

47 Brock, T. J., Browse, J. and Watts, J. L. (2007) Fatty acid desaturation and the regulation of adiposity in Caenorhabditis elegans. Genetics. 176, 865-875

48 Goudeau, J., Bellemin, S., Toselli-Mollereau, E., Shamalnasab, M., Chen, Y. Q. and Aguilaniu, H. (2011) Fatty acid desaturation links germ cell loss to longevity through NHR-80/HNF4 in C. elegans. PLoS Biol. 9, e1000599

49 Watts, J. L. and Browse, J. (2002) Genetic dissection of polyunsaturated fatty acid synthesis in Caenorhabditis elegans. Proc. Natl. Acad. Sci. U. S. A. 99, 5854-5859

50 Capdevila, J. H. and Falck, J. R. (2002) Biochemical and molecular properties of the cytochrome P450 arachidonic acid monooxygenases. Prostaglandins Other Lipid Mediat. 68-69, 325-344

51 Roman, R. J. (2002) P-450 metabolites of arachidonic acid in the control of cardiovascular function. Physiol. Rev. 82, 131-185

52 Spector, A. A. and Norris, A. W. (2007) Action of epoxyeicosatrienoic acids on cellular function. Am. J. Physiol. Cell Physiol. 292, C996-1012

53 Konkel, A. and Schunck, W. H. (2011) Role of cytochrome P450 enzymes in the bioactivation of polyunsaturated fatty acids. Biochim. Biophys. Acta. 1814, 210-222

54 Capdevila, J. H., Falck, J. R. and Harris, R. C. (2000) Cytochrome P450 and arachidonic acid bioactivation. Molecular and functional properties of the arachidonate monooxygenase. J. Lipid Res. 41, 163-181

55 Bonventre, J. V., Huang, Z., Taheri, M. R., O'Leary, E., Li, E., Moskowitz, M. A. and Sapirstein, A. (1997) Reduced fertility and postischaemic brain injury in mice deficient in cytosolic phospholipase A2. Nature. 390, 622-625

56 Nakamura, H., Nemenoff, R. A., Gronich, J. H. and Bonventre, J. V. (1991) Subcellular characteristics of phospholipase A2 activity in the rat kidney. Enhanced cytosolic, mitochondrial, and microsomal phospholipase A2 enzymatic activity after renal ischemia and reperfusion. J. Clin. Investig. 87, 1810-1818

57 Saito, Y., Watanabe, K., Fujioka, D., Nakamura, T., Obata, J. E., Kawabata, K., Watanabe, Y., Mishina, H., Tamaru, S., Kita, Y., Shimizu, T. and Kugiyama, K. (2012) Disruption of group IVA cytosolic phospholipase A(2) attenuates myocardial ischemiareperfusion injury partly through inhibition of TNF-alpha-mediated pathway. Am. J. Physiol. Heart Circ. Physiol. 302, H2018-2030

58 Harris, T. R. and Hammock, B. D. (2013) Soluble epoxide hydrolase: gene structure, expression and deletion. Gene. 526, 61-74

59 Harris, T. R., Aronov, P. A., Jones, P. D., Tanaka, H., Arand, M. and Hammock, B. D. (2008) Identification of two epoxide hydrolases in Caenorhabditis elegans that metabolize mammalian lipid signaling molecules. Arch. Biochem. Biophys. 472, 139149

60 Campbell, W. B. and Fleming, I. (2010) Epoxyeicosatrienoic acids and endotheliumdependent responses. Pflueg. Arch. Eur. J. Physiol. 459, 881-895

61 Xiao, Y. F., Huang, L. and Morgan, J. P. (1998) Cytochrome P450: a novel system modulating $\mathrm{Ca} 2+$ channels and contraction in mammalian heart cells. J. Physiol. 508, 777-792 
62 Avery, L. and Thomas, J. H. (1997) Feeding and defecation. In C. elegans II (Riddle, D. L., Blumenthal, T., Meyer, B. J. and Priess, J. R., eds.), Cold Spring Harbor (NY)

63 Altun, Z. F. and Hall, D. H. (2009) Alimentary system, Pharynx. In WormAtlas (Herndon, L. A., ed.)

64 de Bono, M. and Maricq, A. V. (2005) Neuronal substrates of complex behaviors in C. elegans. Annu. Rev. Neurosci. 28, 451-501

65 Piggott, B. J., Liu, J., Feng, Z., Wescott, S. A. and Xu, X. Z. (2011) The neural circuits and synaptic mechanisms underlying motor initiation in C. elegans. Cell. 147, 922-933

66 Yang, W., Tuniki, V. R., Anjaiah, S., Falck, J. R., Hillard, C. J. and Campbell, W. B. (2008) Characterization of epoxyeicosatrienoic acid binding site in U937 membranes using a novel radiolabeled agonist, $20-{ }^{125} \mathrm{I}-14,15$-epoxyeicosa-8(Z)-enoic acid. J. Pharmacol. Exp. Ther. 324, 1019-1027

67 Chen, Y., Falck, J. R., Manthati, V. L., Jat, J. L. and Campbell, W. B. (2011) 20-Iodo14,15-epoxyeicosa-8(Z)-enoyl-3-azidophenylsulfonamide: photoaffinity labeling of a 14,15-epoxyeicosatrienoic acid receptor. Biochemistry. 50, 3840-3848 


\section{FIGURE LEGENDS}

\section{Figure 1 Detection of recombinant CYP-13A12 and CPR}

(A) Carbon monoxide difference spectra of sodium dithionite reduced microsomal samples isolated form $60 \mathrm{~h}$ old Sf9 insect cell cultures, expressing CYP-13A12 (0.59 nmol/mg protein). (B) Representative Western blot analysis showing recombinant His-tagged CYP13A12 and EMB-8 in single and co-expression. Shown are microsomal preparations and three corresponding homogenate samples isolated at the indicated times. Each lane contains $3 \mu \mathrm{g}$ protein. Besides the marker, recombinant His-tagged cyp4a12 served as control. A 6-histidine epitope tag antibody was used as primary antibody.

\section{Figure 2 Metabolism of AA and EPA by recombinant CYP-13A12}

(A) Representative RP-HPLC chromatogram showing the metabolite pattern formed after incubating $10 \mathrm{nmol}$ AA with $50 \mathrm{pmol}$ of CYP-13A12 in a total volume of $400 \mu \mathrm{l}$ for $10 \mathrm{~min}$ at $25^{\circ} \mathrm{C}$ in the presence of $1 \mathrm{mM}$ NADPH (upper line). None of the metabolites were produced in control samples, where NADPH was omitted (lower line). Main metabolites co-migrated with authentic 19/20-HETE (Rt=15.4 min) and a set of regioisomeric monoepoxides at 23.5 min (14,15-EET) and, e.g., 24.9 min (11,12-EET). Metabolites with uncertain or unknown identity are marked $(*)$. (B) The metabolite pattern was analysed by LC-MS/MS analyses $(\mathrm{n}=3)$. The product distribution indicates the relative contribution of the respective individual metabolites in percent; moreover the metabolite class is indicated. The error bars represent the standard deviation. (C) Representative RP-HPLC chromatogram showing the metabolite pattern formed after incubating 10nmol EPA with 50pmol of CYP-13A12 in a total volume of $400 \mu \mathrm{l}$ for $10 \mathrm{~min}$ at $25{ }^{\circ} \mathrm{C}$ in the presence of $1 \mathrm{mM}$ NADPH (upper line). None of the metabolites were produced in control samples, where NADPH was omitted (lower line). Main metabolites co-migrated with authentic 19/20-HEPE (Rt=13.9 min), 17,18-EEQ (Rt=19.5 $\mathrm{min}$ ) and a set of other regioisomeric EEQs (Rt=21-23 $\mathrm{min})$. Metabolites with uncertain or unknown identity are marked (\#). (D) The metabolite patterns were analysed by LC-MS/MS analyses $(n=3)$. The product distribution indicates the relative contribution of the respective individual metabolites in percent, moreover the metabolite class indicated. The error bars represent the standard deviation.

\section{Figure 3 A metabolisable PUFA is required for the normal O2-ON response}

(A) Speed graph of N2 wild type showing an intact O2-ON response, whereas (B) fat-2(wa17) and (C) fat-3(ok1126) mutants show in each case a defective O2-ON response. Average speed values \pm 2 SEMs (light grey) of animals $(n>50)$ are shown with step changes of $\mathrm{O}_{2}$ between $20 \%$ and $0 \%$ at the indicated times. (D) Speed graph of fat-2(wa17) mutants with the O2-ON response rescued by AA supplementation, and (E) Speed graph of fat-2(wa17) mutants with the O2-ON response rescued by EPA supplementation. (F) Speed graph of fat-2(wa17) mutants with the defective O2-ON response not rescued by ETYA supplementation. Only in case of wild-type as well as AA and EPA exposure of fat-2(wa17), the mean speed within 0 to $120 \mathrm{~s}$ after $\mathrm{O}_{2}$ restoration is increased relative to that before $\mathrm{O}_{2}$ restoration $(P<0.01$, onesided unpaired t-test).

Figure 4 Impact of 17,18-EEQ on the O2-ON response 
(A) Nematode's speed and number of body bends increase in the wild-type in response to a 5 min anoxia/ 2 min reoxygenation stimulus. (B) Supplementation with $10 \mu \mathrm{M}$ 17,18-EEQ restored the locomotion of fat-3(wa22) mutants both in anoxia/reoxygenation and normoxia conditions. $A+B: n \geq 30$ ( $\geq 15$ trials with $n=2$ ), $\pm S D\left({ }^{* * *} P<0.001\right.$, One way ANOVA). (C) An anoxia/reoxygenation stimulus caused in the wild-type a strong increase in the amount of free EPA. (D) The free 17,18-EEQ content is reduced during anoxia but significantly restored in response to reoxygenation. C+D: LC-MS/MS analysis of in each case 5,000 synchronized worms (24 h post L4), n=3, $\pm \mathrm{SD}\left({ }^{*} P<0.05,{ }^{* * *} P<0.001\right.$, One way ANOVA).

Figure 5 17,18-EEQ rescues fat-3(wa22) mutants from movement restriction under normoxia

(A) Chemical structures of compounds used for treatment. (B) Long-term exposure with 80 $\mu \mathrm{M}$ EPA and AA, but not ETYA, a non-metabolisable AA-analogue, rescued the impaired locomotion of the fat-3(wa22) strain, here detected under normoxic conditions. Even added for only $40 \mathrm{~min}$ (short-term exposure), $10 \mu \mathrm{M}$ 17,18-EEQ significantly increased the locomotion of $C$. elegans young fat-3(wa22)adults and (C) in N2 wild-type. Note also the impairment in locomotive behaviour in response to ETYA treatment of the wild-type. Vehicle: $0.3 \%$ DMSO; $\mathrm{n} \geq 30$ (3-5 trials with $\mathrm{n}=10$ ), $\pm \mathrm{SD}\left({ }^{*} P<0.05,{ }^{* *} P<0.01,{ }^{* * *} P<0.001\right.$, One way ANOVA).

Figure 6 Proposed role of CYP-eicosanoids in mediating the O2-ON response

As shown in the present study CYP-eicosanoids such as 17,18-EEQ activate the locomotion behaviour of $C$. elegans. To produce the corresponding metabolites, CYP enzymes require molecular oxygen, NADPH, and free C20-PUFAs. Under normoxic conditions CYPeicosanoid formation is limited by the availability of free C20-PUFAs. Anoxia results in decreased CYP-eicosanoid synthesis due to oxygen-limitation; however, anoxia activates phospholipases releasing free C20-PUFAs from membrane stores that are then available for enhanced CYP-eicosanoid formation in the subsequent reoxygenation phase resulting in a rapidly increased locomotion speed of the nematodes. 
Figure 1
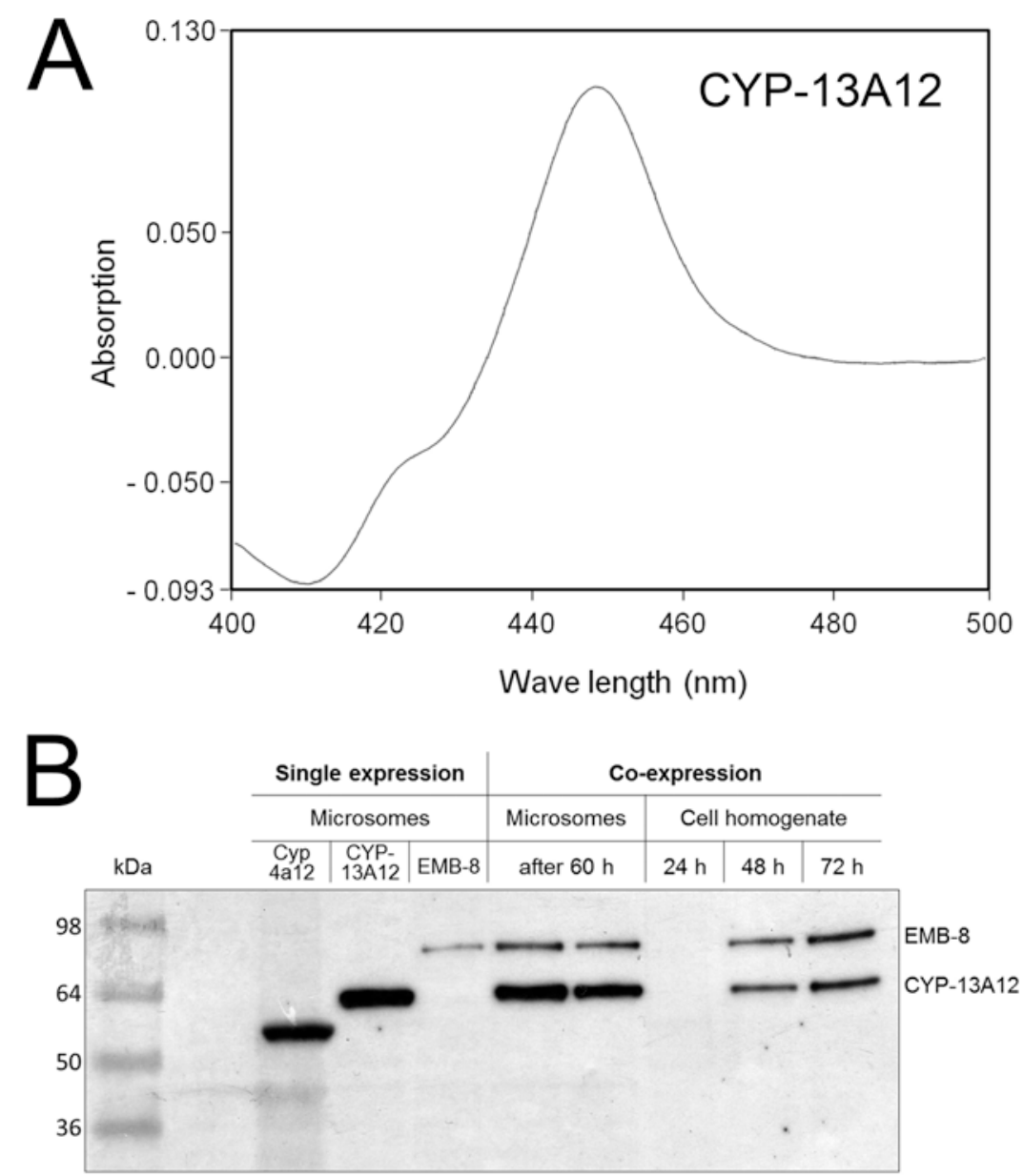
Figure 2

A

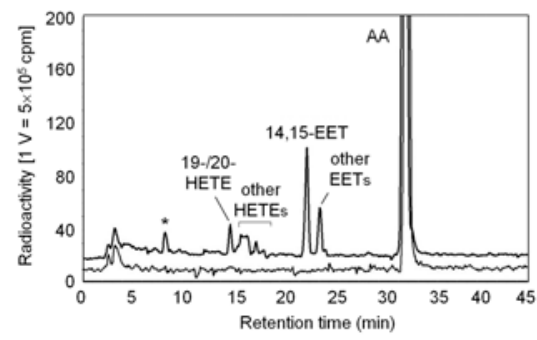

C

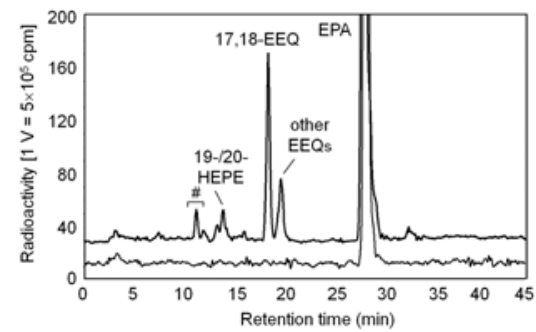

B

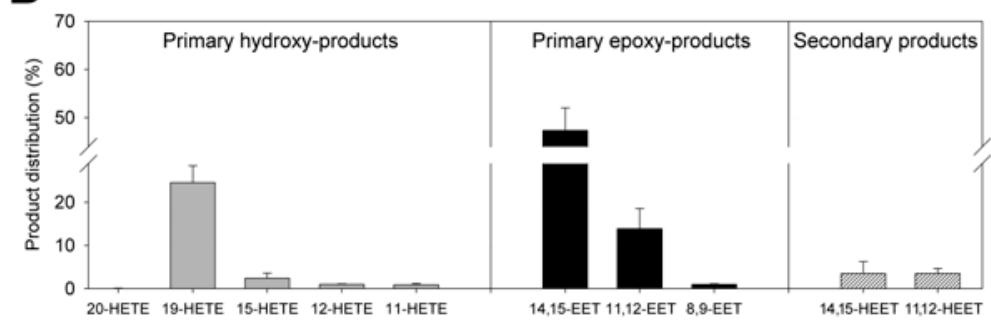

D

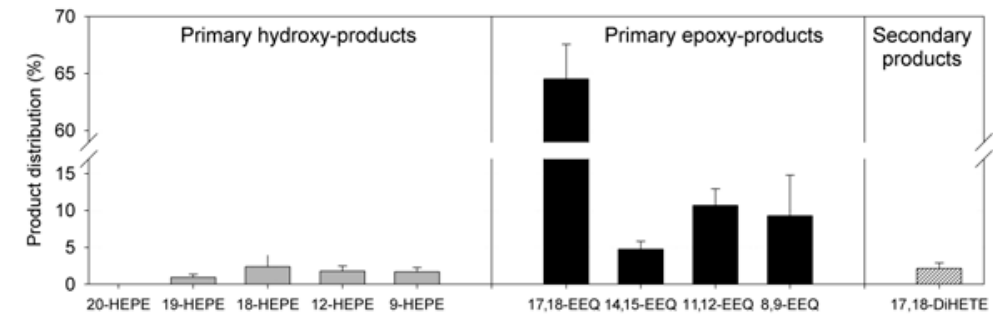


Figure 3
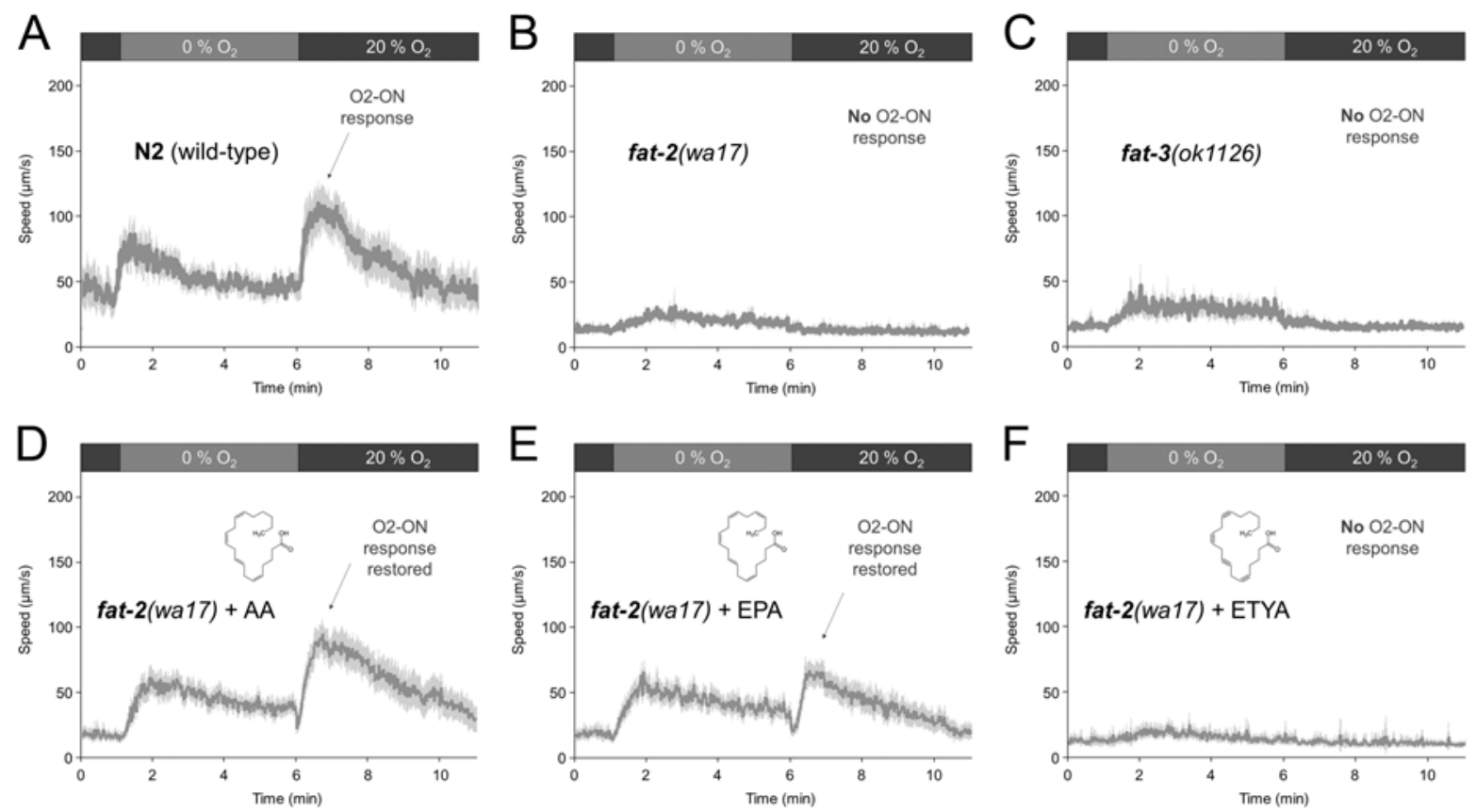


\section{Figure 4}
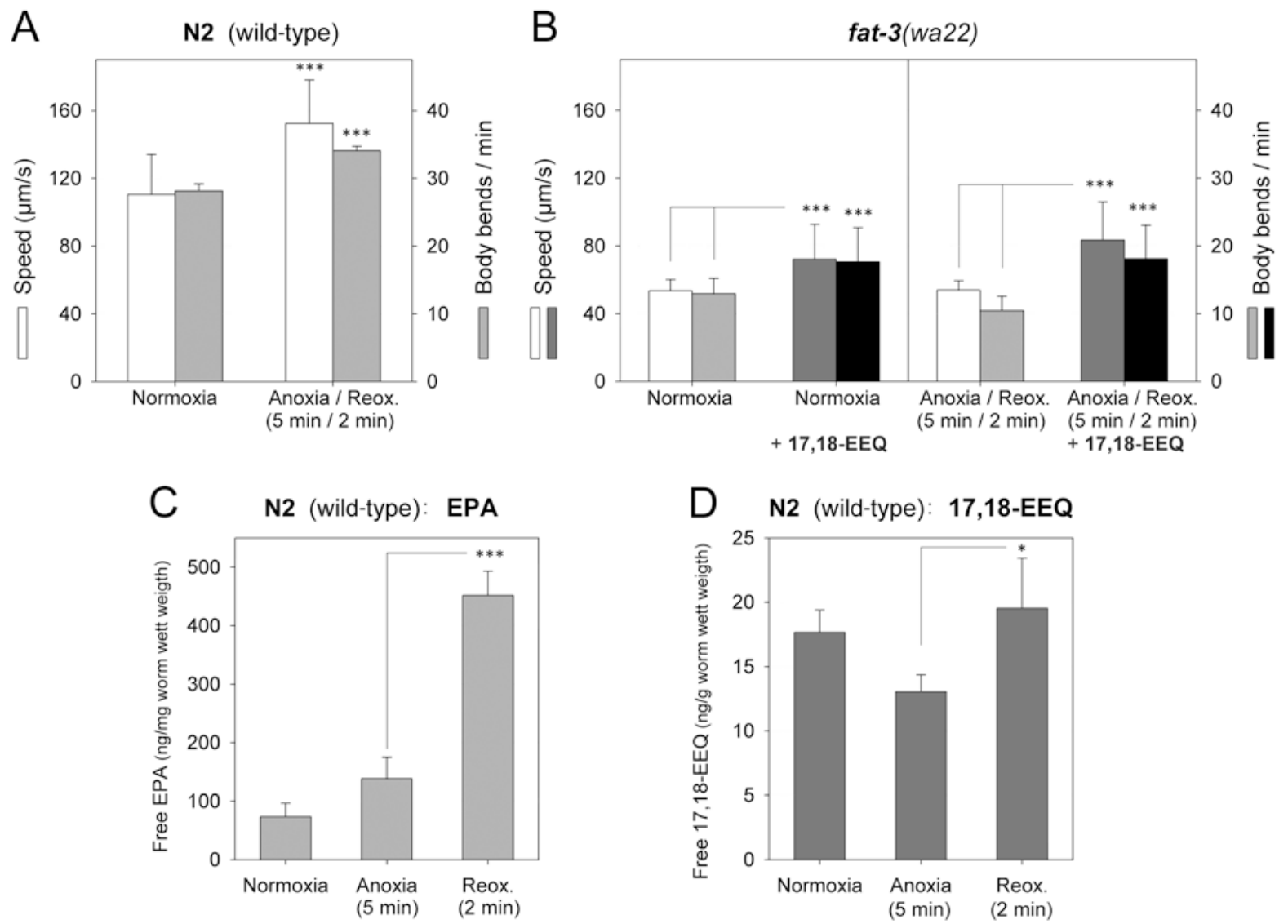

D N2 (wild-type): 17,18-EEQ

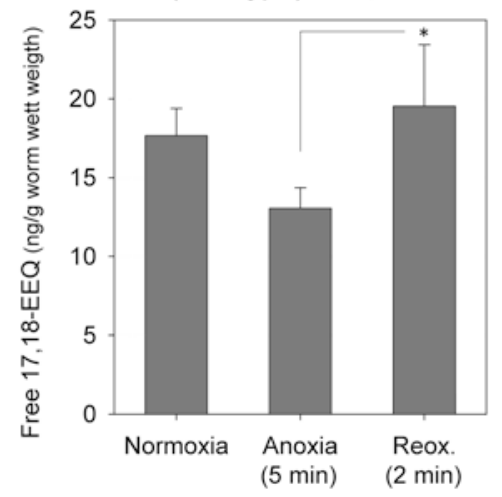


Figure 5

A
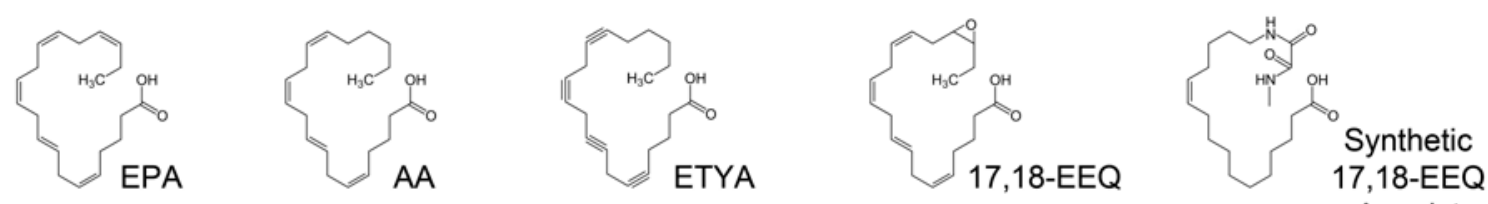

B

fat-3(wa22)

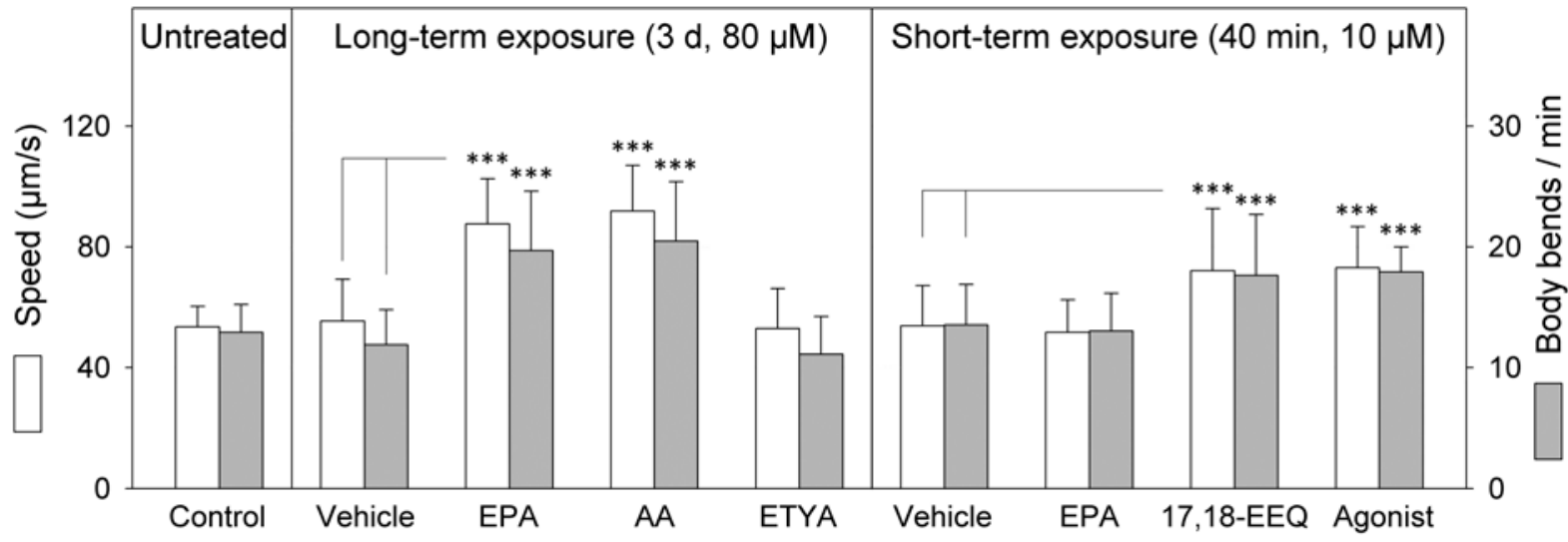

C

N2 (wild-type)

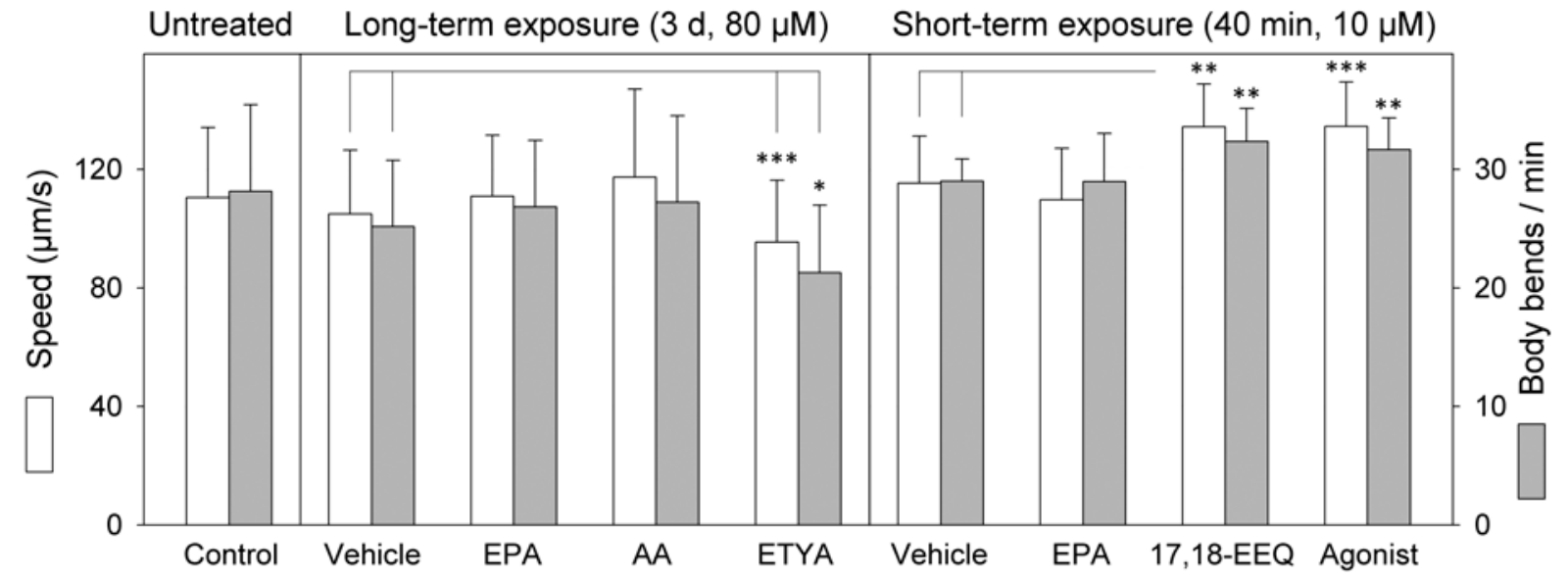


Figure 6

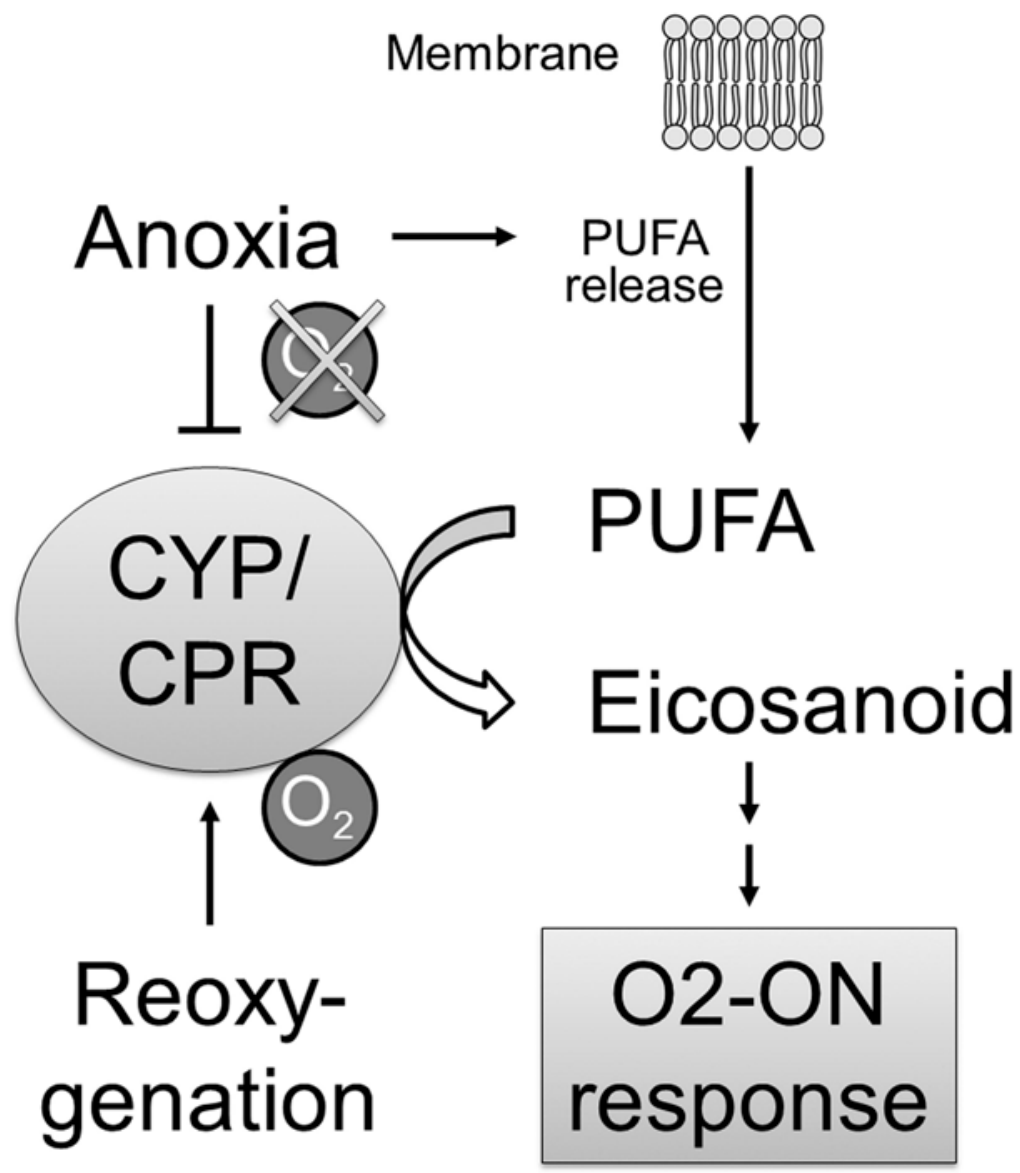

